\title{
Preparation and properties of a new type of flexible epoxy resin based on a molecular network structure
}

\author{
X. F. Zhang ${ }^{*}$, T. Cao, T. H. Zhao, C. Ma, P. Y. Liu \\ Institute of Chemical and Food Engineering, Changsha University of Science and Technology, 410114 Changsha, PR \\ China
}

Received 29 April 2021; accepted in revised form 23 June 2021

\begin{abstract}
In this paper, toluene-diisocyanate-trimer (TDI-T) was utilized to manufacture a new type of epoxy resin with high toughness via the co-polymerization method. In the procedure of preparing bisphenol A epoxy resin, before the reaction between bisphenol A (BPA) and epichlorohydrin (ECH), TDI-T was introduced to react with BPA for embedding flexible segments into the chain of epoxy resin, and obtaining the prepolymers, which are easy to form spatial interweaving network structures, then modified epoxy resin (TDI-T/EP) was manufactured. Mechanical properties, thermomechanical properties, and corrosion resistance of the cured TDI-T/EP were tested and characterized. Due to flexible segments and partial molecular network structure, the material presents high mechanical properties, especially the toughness, and the results show that the maximum tensile strength of cured TDI-T/EP reaches $30.3 \mathrm{MPa}$, and the maximum fracture elongation reaches $48.02 \%$, at the same time the compressive strength arrives at $57.5 \mathrm{MPa}$. Compared with cured E-51, the toughness, strength, and fracture elongation are all strikingly enhanced. At the same time, the cured TDI-T/EP also has an excellent heat resistance and corrosion resistance, which avoided worries at home for its application. This work provides a new method for manufacturing high-toughness epoxy resins.
\end{abstract}

Keywords: molecular engineering, modified epoxy resin, high toughness, 2,4-toluene diisocyanate trimer (TDI-T)

\section{Introduction}

Epoxy resin(EP) is widely used for its outstanding mechanical properties, bonding properties, chemical stability, etc. Concrete crack is a common problem for concrete material [1-3]. Epoxy resin is expected to be used as a concrete crack repair material for its excellent adhesion and strength. However, epoxy resin is brittle and poor impact resistance, which may cause secondary cracking easily. Therefore, it is important to improve the toughness of epoxy resins used as crack repair materials. Currently, there are many methods for toughening epoxy resins. The most common ones are thermoplastic resin toughening [4-8], rubber toughening [9-13], nanoparticle toughening [14-24], interpenetrating network polymer (IPN) toughening [25-31], thermal Toughened liquid crystal polymer (TLCP) toughening [32-34], and core-shell polymer (CSP) toughening $[35,36]$. Unfortunately, these methods are usually based on complex preparation processes. Furthermore, it is difficult to avoid the phase separation between the resin matrix and the third phase particles. In recent years, some progress has been obtained in the modification of molecular structure to toughening epoxy resin. During the synthesis of epoxy resins, flexible groups such as the carbamate group (-NHCOO-) were introduced into the molecular chain of epoxy resin directly; then, the modified epoxy resin was obtained. In the literature of Zhang et al. [37], the intermediate product with flexible chain segments was synthesized by using hexamethylene diisocyanate and bisphenol A, and then the modified epoxy resin

${ }^{*}$ Corresponding author, e-mail: zxf0902@csust.edu.cn

(C) BME-PT 
with high toughness was prepared via co-polymerization method, and the elongation at break reached $124 \%$. And in the other literature of Zhang et al. [38], Epoxy resin E-44 was modified by toluene-diisocyanate-trimer (TDI-T), and a branched polymer with flexible groups was obtained. The elongation at break reached $31.5 \%$, but the impact resistance, tensile strength, and compressive strength reached $76.6 \mathrm{~kJ} / \mathrm{m}^{2}, 184.8 \mathrm{MPa}$, and $40 \mathrm{MPa}$, respectively. In this paper, -NHCOO- as a flexible group was embedded into the molecular chain of block product by reaction between TDI-T and BPA. Then, the block product reacted with $\mathrm{ECH}$ to obtain a new type of epoxy resin (TDI-T/EP), whose molecular chain can extend in three directions in the curing process to form a molecular network structure, which may achieve double toughening effects.

\section{Materials and methods}

\subsection{Materials}

TDI-T was provided by Dongguan Kaixuan Plastic Technology Co., Ltd. (Dongguan, China); BPA, tetramethylammonium bromide, sodium hydroxide, acetone, and epichlorohydrin (ECH) were supplied by Aladdin Industrial Co. (Shanghai, China); Low molecular weight polyamide was used as curing agent and was purchased from Dingyuan County Danbao Resin Co., Ltd. (Jiangsu, China). E-51 came from Baling Petrochemical Co., Ltd. (Hunan, China).

\subsection{Experiment procedure}

\subsubsection{Block reaction}

In a nitrogen atmosphere, ECH and BPA were dissolved into a flask and gradually heated to $50{ }^{\circ} \mathrm{C}$. Then TDI-T was andante added into the flask. The stirring was turned on. One hour later, a transparent product was formed.

\subsubsection{Epoxy resin modification}

Elevate the above product's temperature to $70^{\circ} \mathrm{C}$. Then an appropriate amount of catalyst tetramethylammonium bromide was added into the flask. Keep it at $70^{\circ} \mathrm{C}$ for several hours. The color of the obtained product was still transparent, and the viscosity had no obvious change. Then naturally cooled to $60^{\circ} \mathrm{C}$, $\mathrm{NaOH}$ solution was dropped into the flask through a constant pressure dropping funnel. A few hours later, the solution became light yellow, and the viscosity increased significantly.

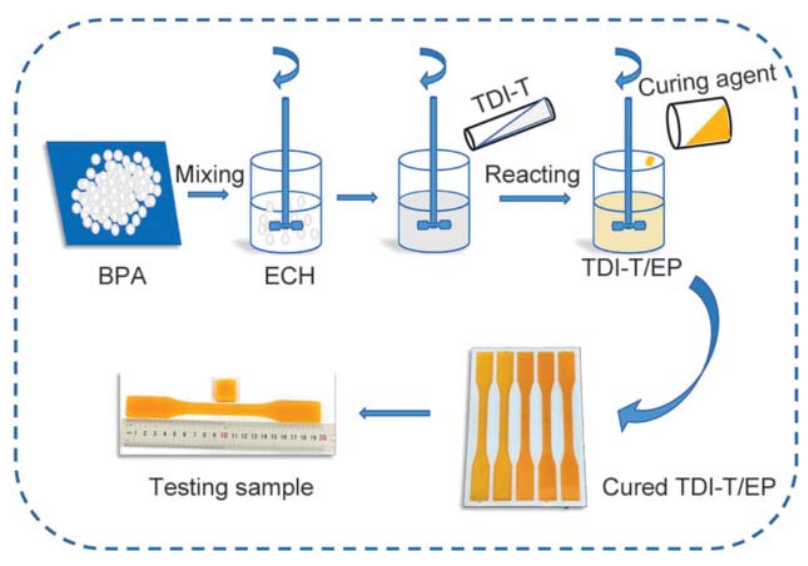

Figure 1. Synthetic procedure diagram of TDI-T/EP cured product.

\subsubsection{Post-processing}

In order to remove unreacted solvents and impurities generated by the reaction, the product was washed with distilled water at $50{ }^{\circ} \mathrm{C}$ until its $\mathrm{pH}$ value reached 7 . Then the product was distilled under reduced pressure and taken out and sealed for later use.

\subsubsection{Curing}

At room temperature, a curing agent (polyamide) was mixed with TDI-T/EP prepared in the above steps in a ratio of 7:10. And then, a curing accelerator (DMP-30) was added. Then the cured product of the modified epoxy resin was synthesized.

\section{Results and discussion}

\subsection{FT-TR spectra of TDI-T/EP and cured samples}

Infrared spectra were obtained on a Perkin Elmer Spectrum 100 FT-IR spectrometer(Germany) with the frequency range of $4000-500 \mathrm{~cm}^{-1}$. The FT-IR spectra of TDI-T, block reaction products, and TDI-T/ EP are shown expectedly in Figure 2. Clearly, there is an absorption peak near $2270 \mathrm{~cm}^{-1}$ in the infrared spectrum of TDI-T, which confirms the existence of $-\mathrm{NCO}$. On the contrary, there is no absorption peak near $2270 \mathrm{~cm}^{-1}$ in the infrared spectrum of the block product, indicating the disappearance of -NCO after the block reaction. At the same time, there is an absorption peak at $1720 \mathrm{~cm}^{-1}$ in the block reaction product spectrum, which is the absorption peak of $\mathrm{C}=\mathrm{O}$ in $-\mathrm{NHCOO}$, indicating the successful reaction of $-\mathrm{NCO}$ in TDI-T and -OH in BPA. In the infrared spectrum of TDI-T/EP, the absorption peaks at 1450, 1500 , and $1600 \mathrm{~cm}^{-1}$ all indicate the existence of 


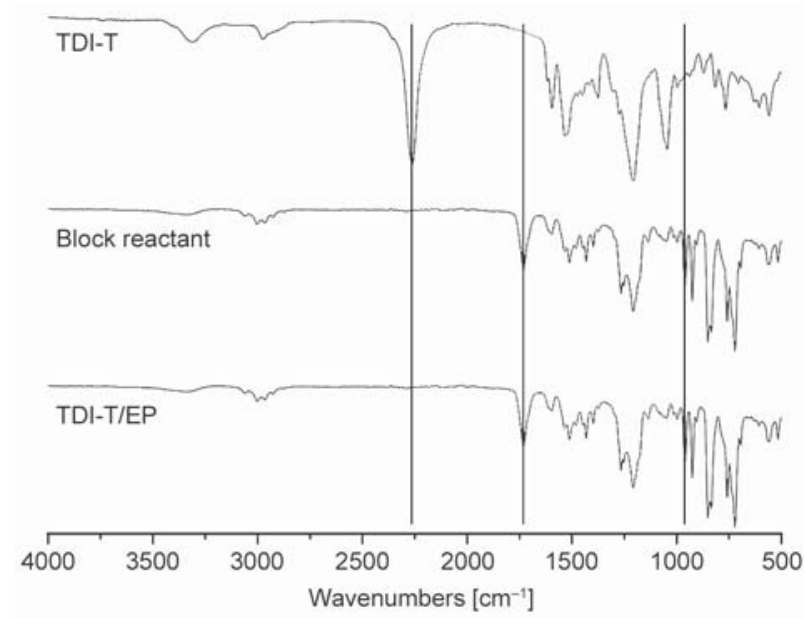

Figure 2. FT-TR Spectra of TDI-T, Block reaction products and TDI-T/EP.

benzene rings. Obviously, the absorption peak at $910 \mathrm{~cm}^{-1}$ in the infrared spectrum of TDI-T/EP is the absorption peak of an epoxy group (-COC).

The chemical structure of the TDI-T /EP was also studied by ${ }^{1} \mathrm{H}-\mathrm{NMR}$ and ${ }^{13} \mathrm{C}-\mathrm{NMR}$ (as shown in Figure 3). The peak at $7.1 \mathrm{ppm}$ corresponds to the hydrogen of benzene rings, And the chemical shift at $7.36 \mathrm{ppm}$ is assigned to amide proton; there is also the chemical shift representing the protons in the epoxy group, which appeared at $\delta=5.65 \mathrm{ppm}$. In addition, two peaks located at 125.6 and $69.5 \mathrm{ppm}$ in the ${ }^{13} \mathrm{C}$-NMR spectrum can be clearly observed, and they are associated to the carbon atoms on benzene rings and epoxy groups. Combined with the infrared spectrum, it can be determined that the final product is the target product of this experiment, and the modified epoxy resin TDI-T /EP is successfully synthesized. Therefore, the procedure of modified epoxy resin can be derived from Figure 4. -NCO reacts with $-\mathrm{OH}$ to generate a block reaction product

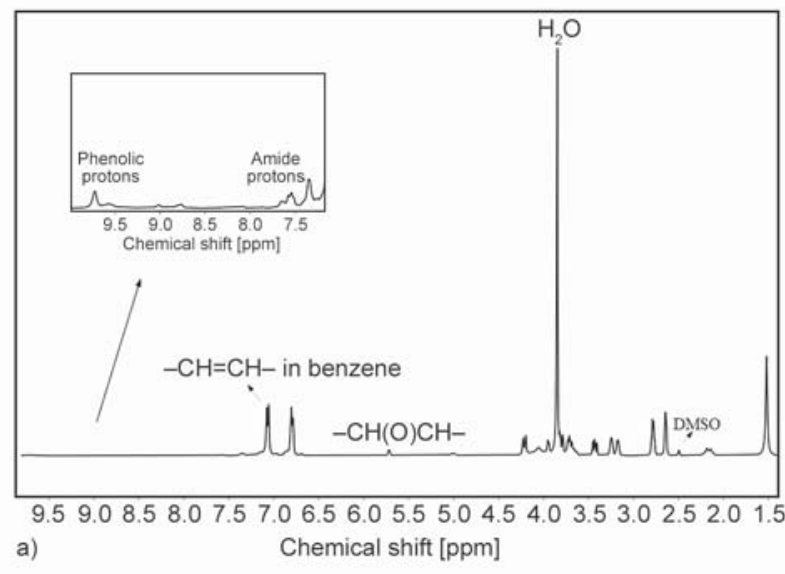

Figure 3. ${ }^{1} \mathrm{H}$ (a) and ${ }^{13} \mathrm{C}$ (b) NMR spectra of the TDI-T/EP. containing flexible -NHCOO groups. Then, the block reaction product and $\mathrm{ECH}$ undergo reactions to generate TDI-T/EP.

\subsection{Mechanical properties of the cured TDI-T/EP}

The mechanical properties of cured TDI-T/EP were tested on a universal testing machine (Metes Industrial Systems Co., Ltd, China) according to the standard of GB/T2567-2008 at room temperature. Formulations of TDI-T/EP composites can be seen in Table 1. Choosing polyamide as the curing agent, the TDI-T/EP was cured at room temperature. The compressive strength of cured neat EP and TDI-T/EP were shown in Figure 5. It can be seen that neat EP has the lowest compressive strength of $29.8 \mathrm{MPa}$; when the ratio of BPA to TDI-T is 1:0.1, the compressive strength reached the highest value of $57.5 \mathrm{MPa}$, which have increased by $92.95 \%$. Overall, as the addition amount of TDI-T increases, the compressive strength decreases. Among the five samples of modified epoxy resins, a sample of TDI-T- 0.5 has the lowest compressive strength at $37.8 \mathrm{MPa}$, but it is still $26.8 \%$ higher than neat EP.

The stress-strain curve of cured neap EP and TDI-T/ EP during the stretching process was showed in Figure 6 , and the tensile strength and the elongation at break of these samples were shown in Table 2. It can be seen from Figure 6 that with an increase of the ratio of BPA to TDI-T, tensile strength increases firstly and then decreases, while elongation at break steadily increases. Tensile strength and elongation at break of the cured neap EP (TDI-T-0) are $14.4 \mathrm{MPa}$ and $5.12 \%$. Respectively, tensile strength and elongation at break of cured TDI-T/EP have improved. When the ratio of BPA to TDI-T is 1:0.2, tensile

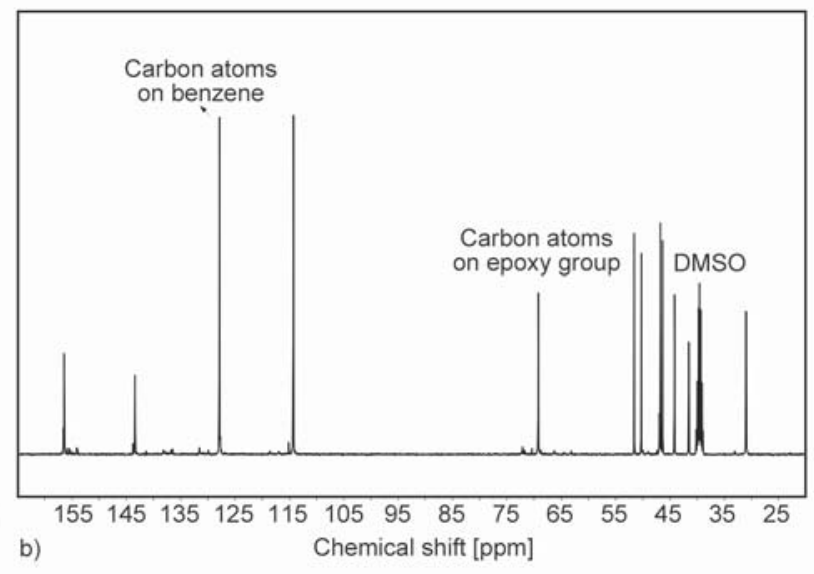




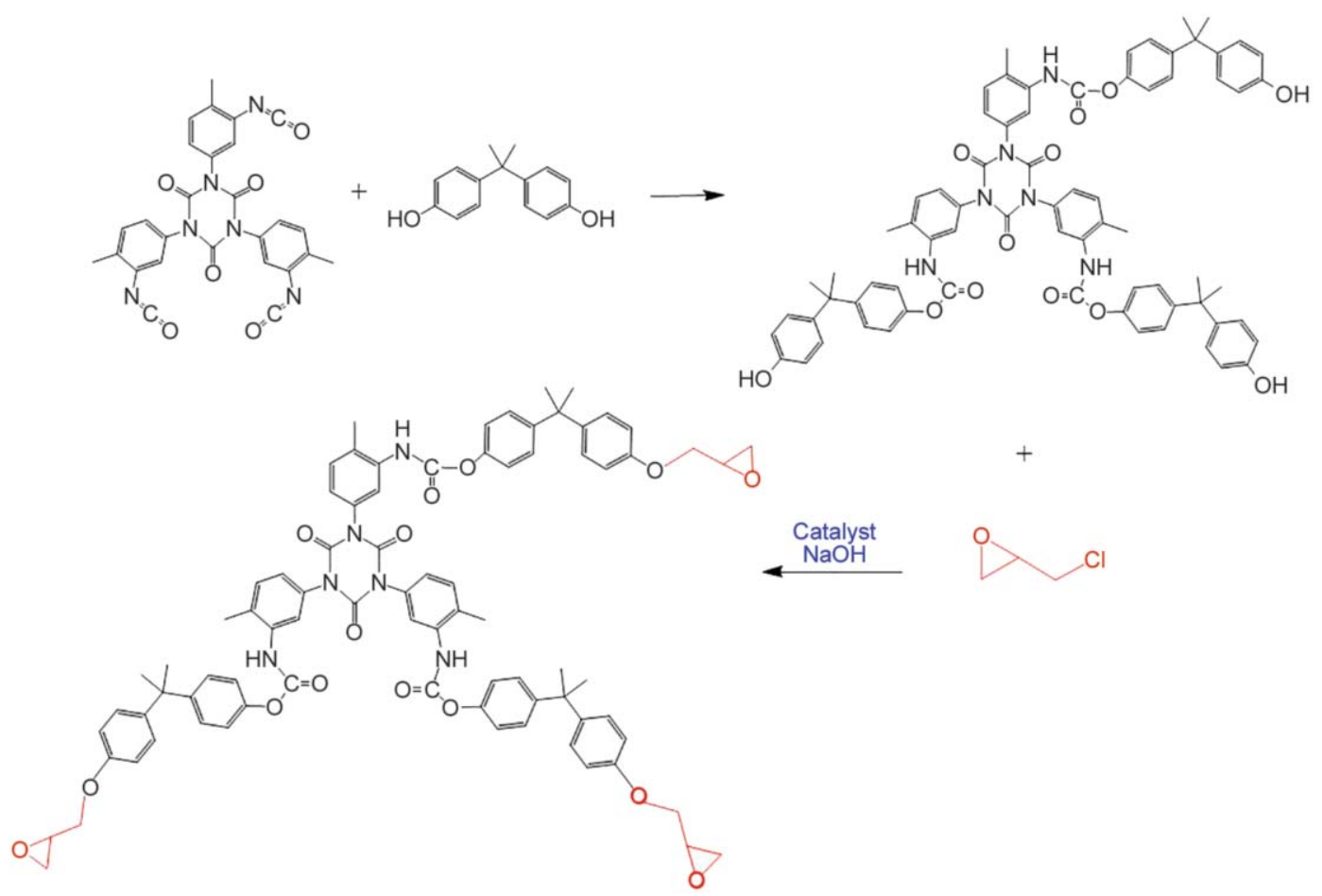

Figure 4. Reaction flow chart for preparing tough TDI-T/EP.

Table 1. Formulations of TDI- T/EP composites.

\begin{tabular}{|l|c|c|c|}
\hline Sample & $\begin{array}{c}\text { BPA } \\
{[\mathbf{m o l}]}\end{array}$ & $\begin{array}{c}\text { ECH } \\
{[\mathbf{m o l}]}\end{array}$ & $\begin{array}{c}\text { TDI-T } \\
{[\mathbf{m o l}]}\end{array}$ \\
\hline TDI-T-0.1 & 1 & 15 & 0.1 \\
\hline TDI-T-0.2 & 1 & 15 & 0.2 \\
\hline TDI-T-0.3 & 1 & 15 & 0.3 \\
\hline TDI-T-0.4 & 1 & 15 & 0.4 \\
\hline TDI-T-0.5 & 1 & 15 & 0.5 \\
\hline
\end{tabular}

strength reaches a maximum value of $30.3 \mathrm{MPa}$, elongation at break reaches $16.59 \%$. As the addition amount of TDI-T increasing, the tensile strength begins to drop, and the elongation at break still increases. When the molar ratio of BPA to TDI-T is 1:0.5, the elongation at break reaches $48.02 \%$, which is $5.12 \%$ higher than neat epoxy resin.

The increase of toughness of TDI-T/EP can be attributed to the two aspects: carbamate groups in the

Table 2. Tensile strength and elongation at break of cured neat EP and TDI-T/EP.

\begin{tabular}{|ll|c|c|c|c|c|c|}
\hline \multicolumn{2}{|c|}{ Sample } & TDI-T-0 & TDI-T-0.1 & TDI-T-0.2 & TDI-T-0.3 & TDI-T-0.4 & TDI-T-0.5 \\
\hline Tensile strength & {$[\mathrm{MPa}]$} & 14.40 & 22.20 & 30.30 & 19.80 & 15.20 & 11.00 \\
\hline Elongation at break & {$[\%]$} & 5.12 & 8.21 & 16.59 & 20.17 & 39.10 & 48.02 \\
\hline
\end{tabular}

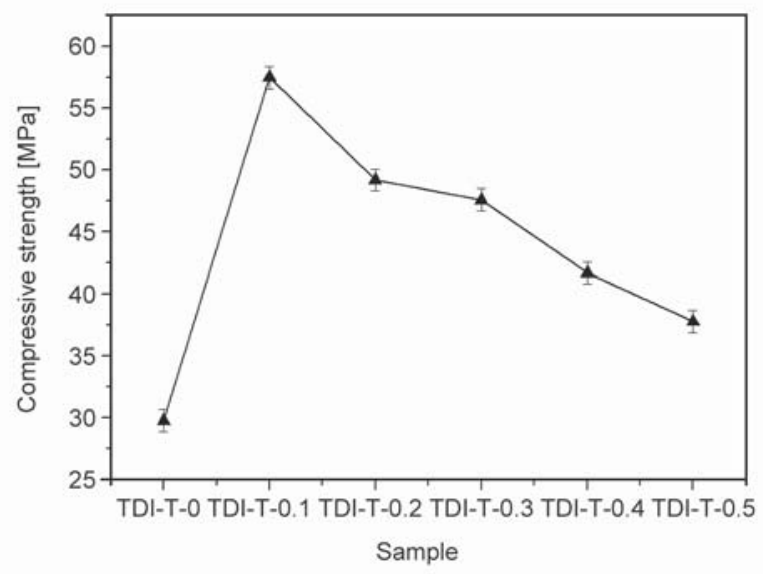

Figure 5. Compressive strength of cured neat EP and TDI-T/EP.

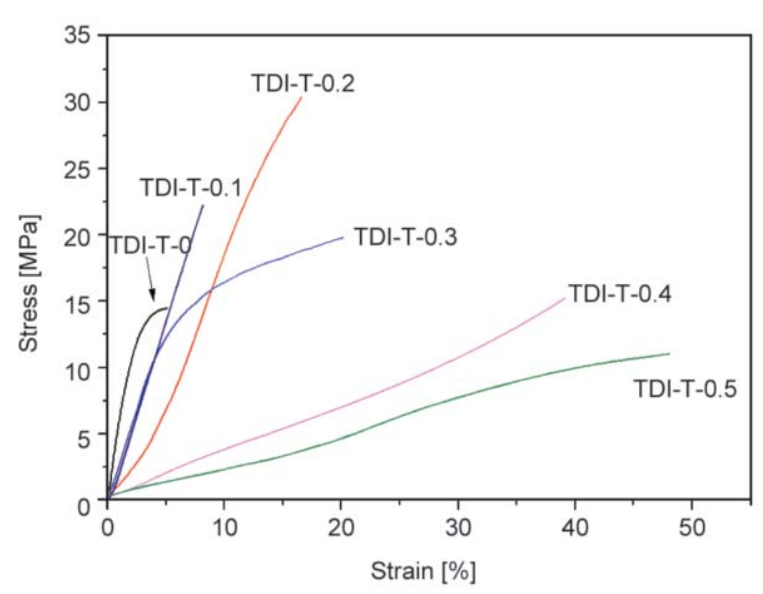

Figure 6. Stress-strain curves of cured neat EP and TDI-T/ EP in process of stretching. 


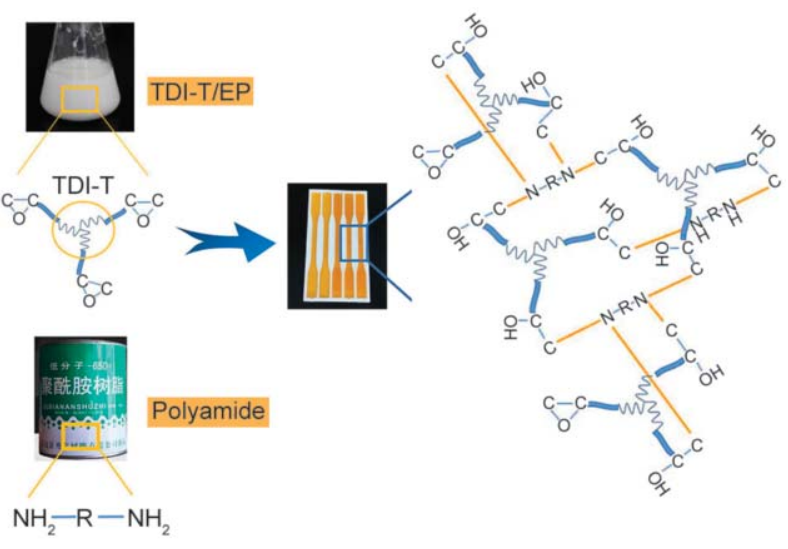

Figure 7. Schematic diagram of curing reaction.

molecular structure of TDI-T/EP are flexible groups, and a partial molecular network structure as shown in Figure 6 is formed. Molecular network structure can provide available space for stretching in the curing process. Flexible segments in the molecule are interspersed and entangled in the space of the network structure. When subjected to external pressure or tension, the network structure will work together to resist external forces, which is the reason for the increase in tensile strength and compressive strength. TDI-T contains three active isocyanate groups. When TDI-T is embedded into the epoxy resin, the new epoxy resin can extend in three directions at the same time during the curing process and form a partial network structure. In the sample of TDI-T-0.1, the molecular network structure is incomplete, which leads to a small stretchable space. At the same time, the sample has a high crosslink density which leads to greater compressive strength, but its tensile strength is not the maximum. However, the molecular network structure is better developed in TDI-T-0.2, which leads to an increase in the space that can be stretched and compressed. Therefore, the compressive strength of TDI-T- 0.2 decreases, but tensile strength reaches the maximum value. Samples of TDI-T-0.3, TDI-T/EP-0.4, and TDI-T-0.5 might have synthesized a partial linear molecular network structure, resulting in a gradual increase in elongation at break but a decrease in tensile strength.

\subsection{Scanning electron microscopy}

Scanning electron microscope (SEM) photographs were got on an S-3000N scanning electron microscope (SEM, Japan) at the accelerating voltage of $20 \mathrm{kV}$. The tensile section of the neat EP was shown in Figure 8. The section is smooth. Cracks are elongated and arranged regularly. It could be inferred that cured neat EP dose not prevented from crack propagation during crack propagation process, showing a typical brittle fracture. It can be clearly observed from the figure that the surface of the TDI-T/EP becomes rough and uneven compared to neat epoxy resin. And there are more convex curled edges on the surface, while the substrate has thin strip-like branches, Which shows that when the material is subjected to external force, the crack propagation is obstructed to a certain extent, showing a typical ductile fracture. The material is flexible. The thin strip-like branches may be the macroscopic performance of the introduction of flexible segments in the modified epoxy resin. When subjected to an outside force, the material section needs to resist the force to dissipate stress as much as possible to prevent crack propagation. When external force reaches a certain level, the crosslinked network form by EP main chain would be stretched until it is broken. At the same time, the flexible segment withstands the external force continuously until it is pulled out of the epoxy resin matrix. It can be clearly observed that section morphology of TDI-T0.2 has a more obvious ductile fracture feature than other samples, which is consistent with its maximum tensile strength $(30.3 \mathrm{MPa})$ in the tensile strength test.

\subsection{Differential scanning calorimetry}

DSC analysis was carried out on a DSC Q2000 (Netzsch Corporation, Germany) equipped with a thermal analysis data station at a heating rate of $5^{\circ} \mathrm{C} / \mathrm{min}^{-1}$ under $\mathrm{N}_{2}$ atmosphere. Glass transition temperature $\left(T_{\mathrm{g}}\right)$ is an important indicator of thermal performance. As shown in Figure 9, the $T_{\mathrm{g}}$ of cured neat EP and TDI-T/EP were measured. According to literature, $T_{\mathrm{g}}$ of polymers with good flexibility is lower; the two are negatively correlated. The experiment reveals that $T_{\mathrm{g}}$ of TDI-T/EP is lower than that of neat EP. On the one hand, the flexible structure in the modified epoxy resin is mainly $\mathrm{C}=\mathrm{O}$ bonds and $\mathrm{C}-\mathrm{O}-\mathrm{C}$ bonds. As the amount of TDI-T increasing, the amount of $\mathrm{C}=\mathrm{O}$ bonds and $\mathrm{C}-\mathrm{O}-\mathrm{C}$ bonds also increases, resulting in a reduction of $T_{\mathrm{g}}$. First of all, isocyanate groups of TDI-T have strong reactivity. As the amount of TDI-T increases, free isocyanate groups in the system also increases, resulting in side reactions, such as reacting with isocyanate groups and water in EP to form substituted urea. --NCO does not react with $-\mathrm{NHCOO}$ at room temperature, but when the temperature rises, it will gradually start 

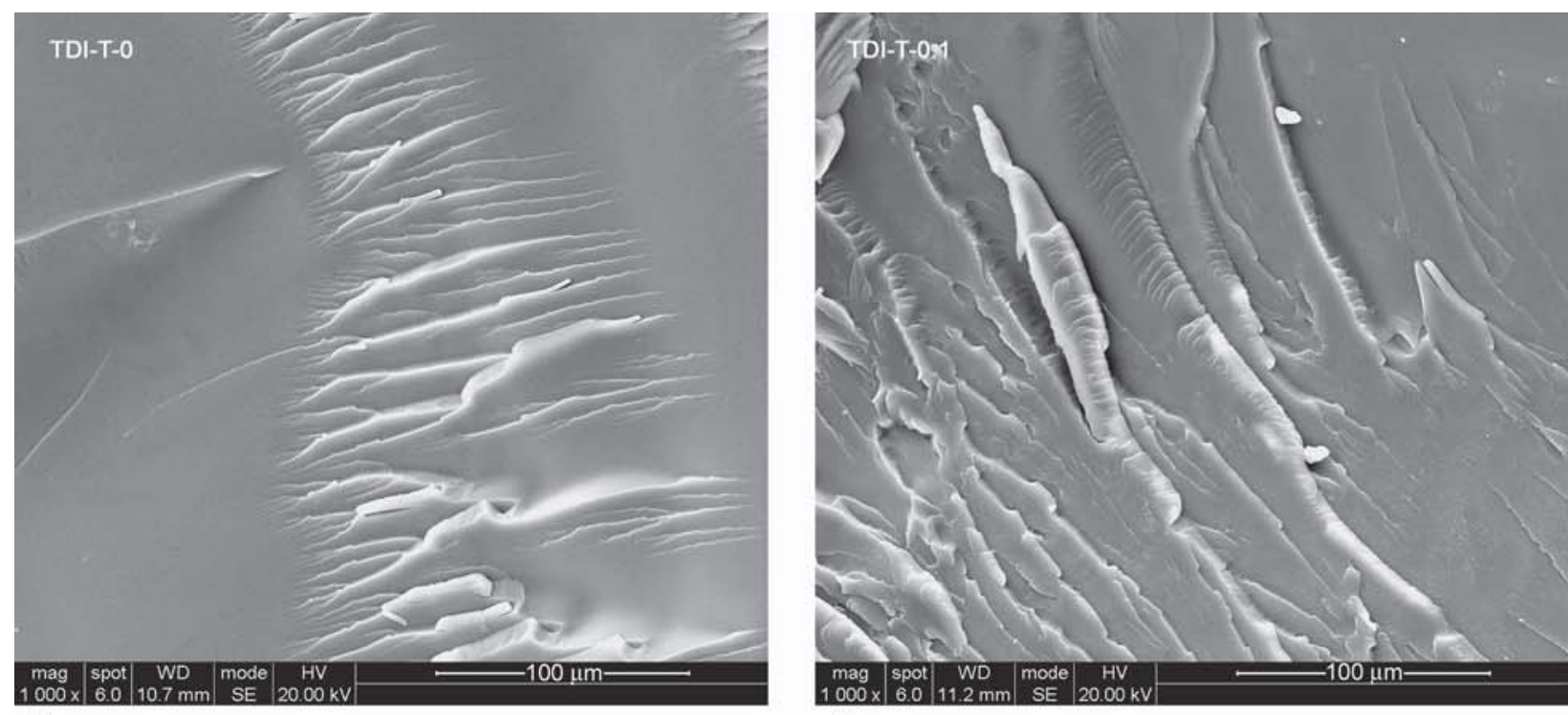

a)

b)
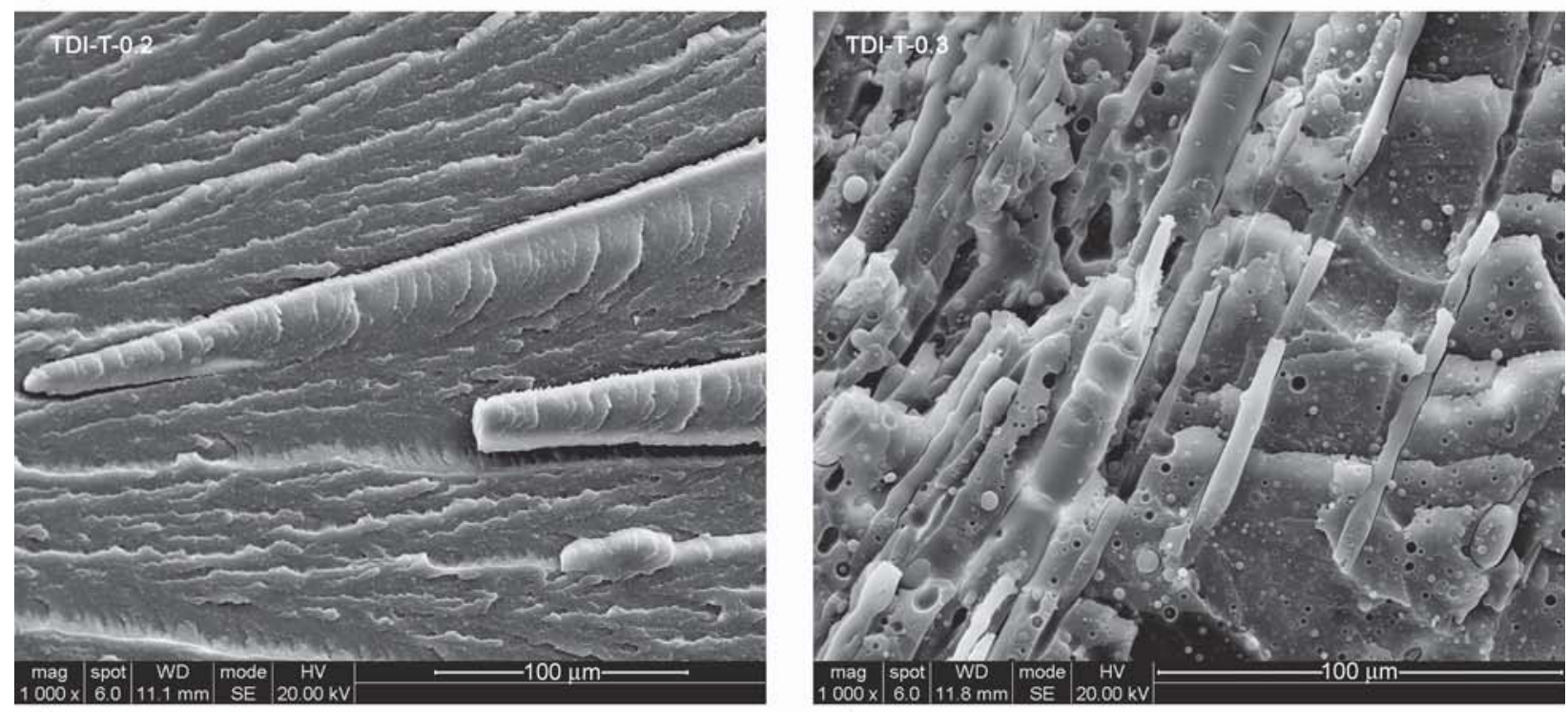

c)

d)

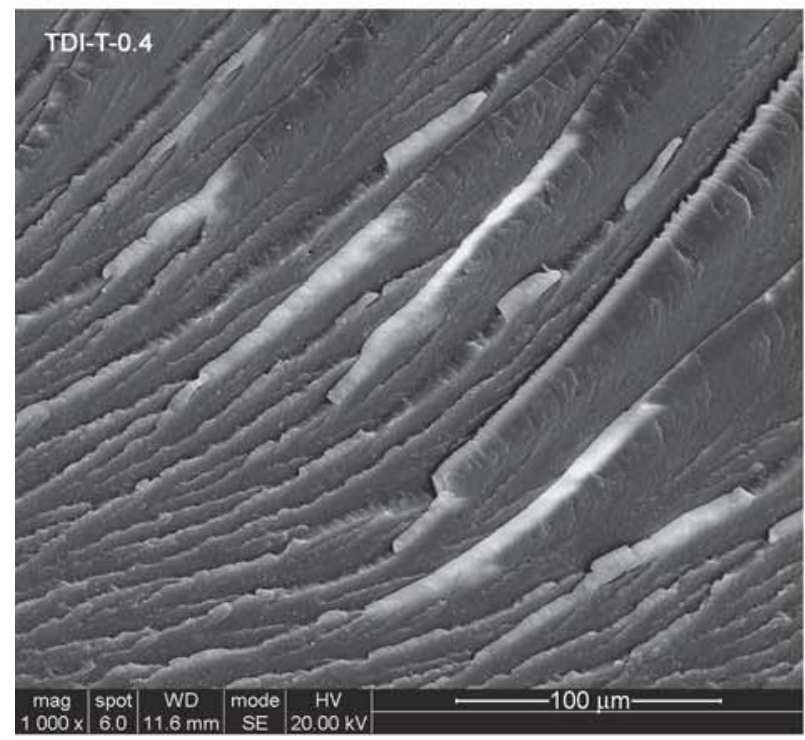

e)

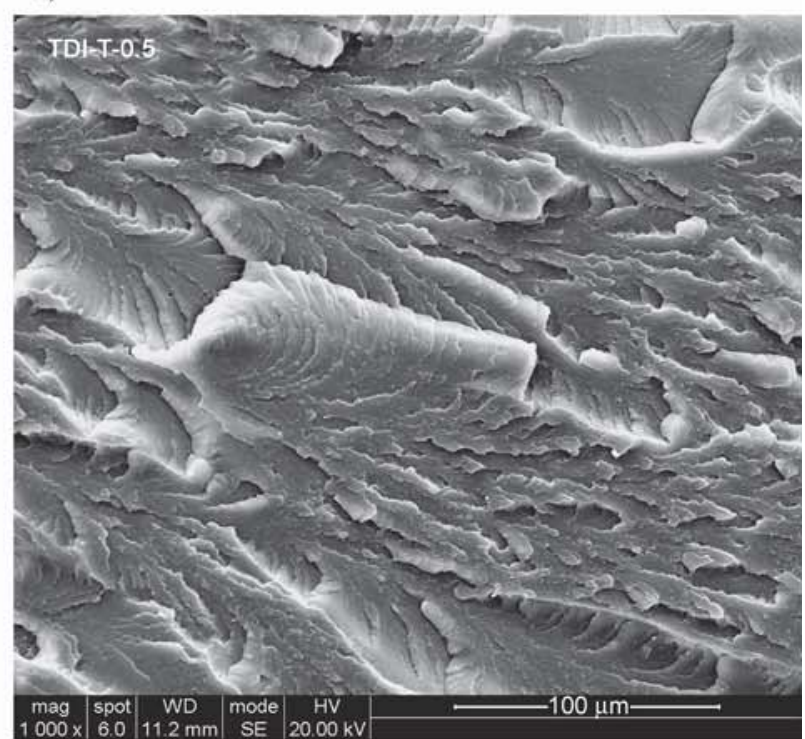

f)

Figure 8. Scanning electron microscope images of the fracture surfaces of cured neat EP and TDI-T/EP. a) TDI-0; b) TDI-0.1; c) TDI-0.2; d) TDI-0.3; e) TDI-0.4; f) TDI-0.5. 


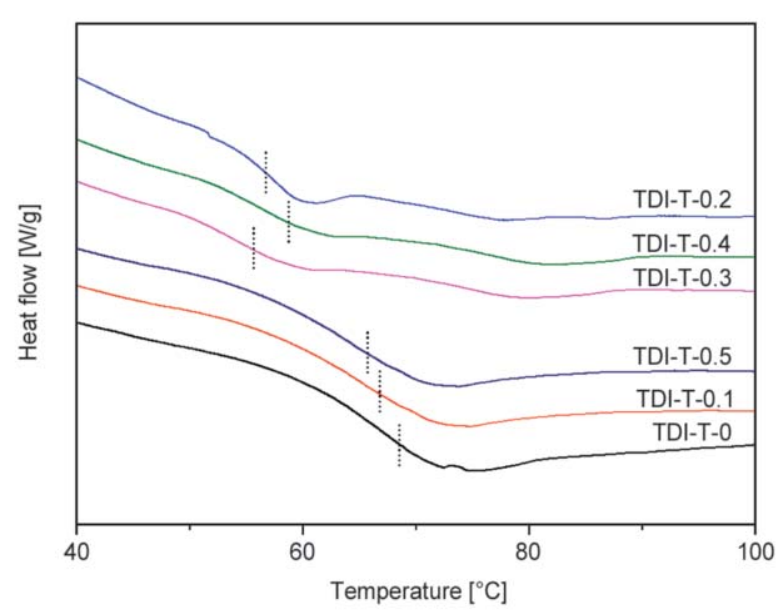

Figure 9. Differential scanning calorimetry chart of the fracture surfaces of cured neat EP and TDI-T/EP.

to react. The increase of the above side reactions will affect the formation of the target product and eventually leads to a decrease of $T_{\mathrm{g}}$. However, a decrease of $T_{\mathrm{g}}$ is within a reasonable range, which does not affect the performance.

\subsection{Corrosion resistance test}

In order to test the corrosion resistance of modified epoxy resin, cured TDI-T/EP was placed in deionized water, sulfuric acid solution( $(10 \mathrm{wt} \%)$, sodium hydroxide solution(10 wt $\%$ ), and sodium chloride solution $(10 \mathrm{wt} \%)$ at room temperature for $100 \mathrm{~h}$, and then took it out and dried naturally. The determination of corrosion resistance follows Chinese national standards GB/T2567-2008. There was no obvious abnormality after drying. Mechanical properties and quality loss tests were performed. Results were shown in Figures 10-12. After immersed and corroded in deionized water and acid-base salts, the changes of tensile properties and compression properties of

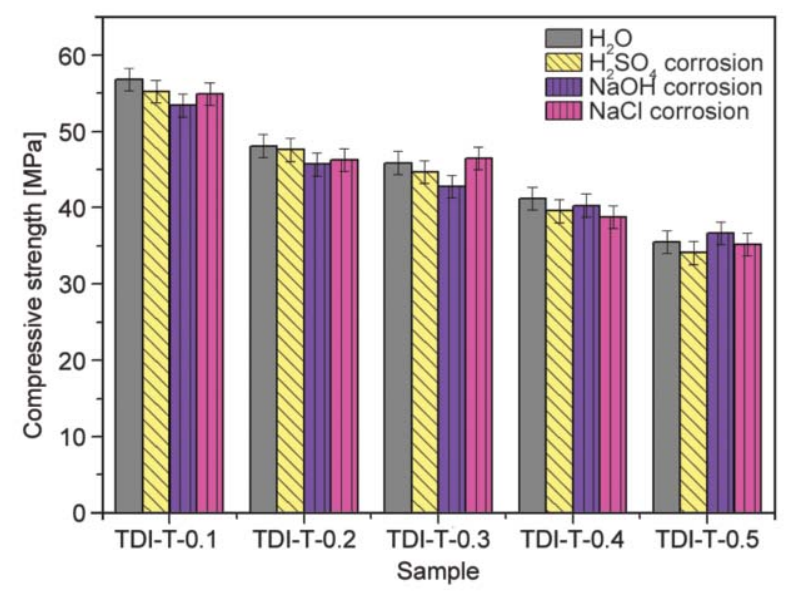

Figure 10. Compressive strengths of cured TDI-T/EP after soaking in $\mathrm{H}_{2} \mathrm{SO}_{4}, \mathrm{NaOH}$, and $\mathrm{NaCl}$ solutions.

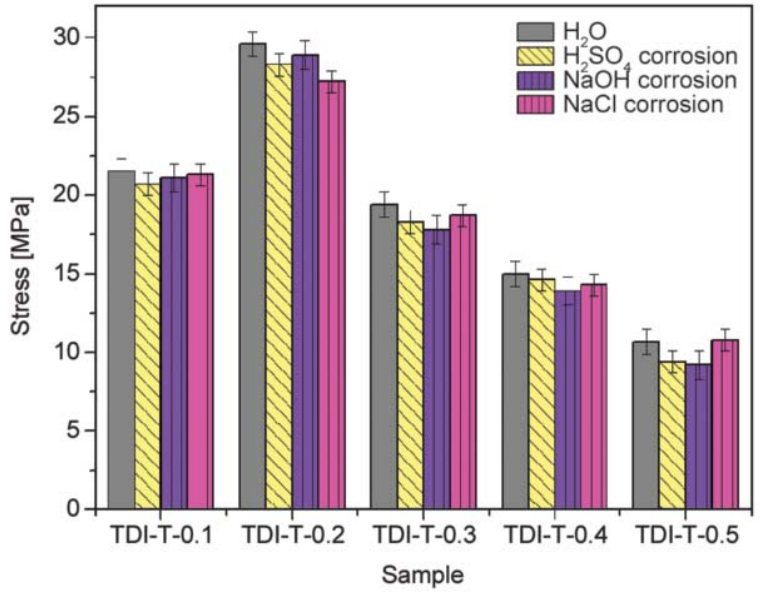

Figure 11. The tensile strengths of cured TDI-T/EP after soaking in $\mathrm{H}_{2} \mathrm{SO}_{4}, \mathrm{NaOH}$, and $\mathrm{NaCl}$ solutions.

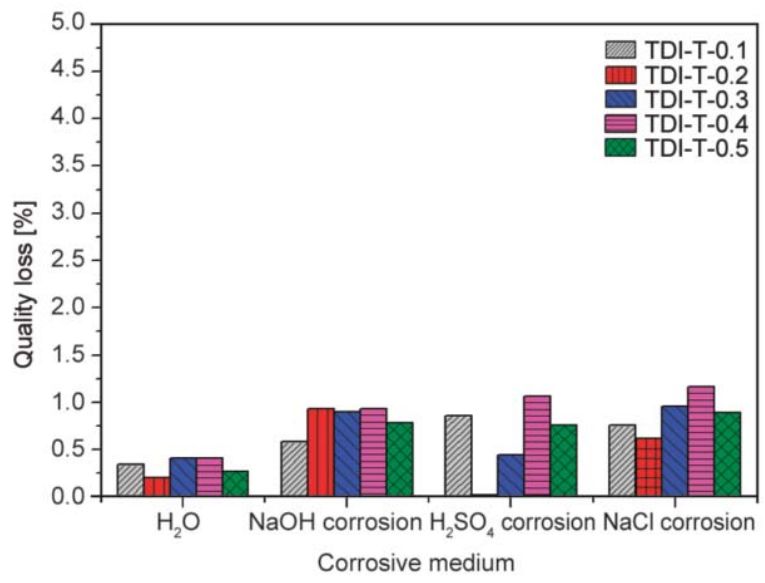

Figure 12. Quality loss rate of cured TDI-T/EP after corrosion.

TDI-T/EP are within a reasonable range. Mechanical properties of TDI-T/EP are not destroyed. The quality loss rate of cured TDI-T/EP after corrosion was shown in Figure 12. The quality loss rate of samples after corrosion was very low. In general, modified epoxy resin has good corrosion resistance.

\section{Conclusions}

In summary, for the first time, a new type of epoxy resin TDI-T/EP with high toughness was prepared via the co-polymerization method. Due to the flexible groups and the molecular network structure, the compressive strength of the TDI-T/EP reaches 57.2 MPa, and the tensile strength reached $30.3 \mathrm{MPa}$, the elongation at break reaches $48.02 \%$, which could meet different needs. In addition, TDI-T/EP also has excellent corrosion resistance and thermal stability. The present work provides a convenient and simple pathway to synthesize high toughness epoxy resin, which was hopefully applied in many fields. 


\section{References}

[1] Wei C., Wojnar C. S. Wu C.: Hydro-chemo-mechanical phase field formulation for corrosion induced cracking in reinforced concrete. Cement and Concrete Research, 144, 106404/1-106404/21 (2021).

https://doi.org/10.1016/j.cemconres.2021.106404

[2] Demir B., Beggs K. M., Fox B. L., Servinis L., Henderson L. C., Walsh T. R.: A predictive model of interfacial interactions between functionalised carbon fibre surfaces cross-linked with epoxy resin. Composites Science and Technology, 159, 127-134 (2018). https://doi.org/10.1016/j.compscitech.2018.02.029

[3] Chauhan A., Sharma U. K.: Crack propagation in reinforced concrete exposed to non-uniform corrosion under real climate. Engineering Fracture Mechanics, 248, 107719/1-107719/25 (2021). https://doi.org/10.1016/j.engfracmech.2021.107719

[4] Li S., Hsu B-A., Li F., Li C. Y., Harris F. W., Cheng S. Z. D.: A study of polyimide thermoplastics used as tougheners in epoxy resins - Structure, property and solubility relationships. Thermochimica Acta, 340-341, 221-229 (1999).

https://doi.org/10.1016/S0040-6031(99)00266-X

[5] Yang W., Fu Z., Sun Y.: Bridging toughening of epoxy resins by dispersed thermoplastics. Acta Mechanica Sinica, 5, 332-342 (1989). https://doi.org/10.1007/BF02488006

[6] Kunz S. C., Beaumont P. W. R.: Low-temperature behaviour of epoxy-rubber particulate composites. Journal of Materials Science, 16, 3141-3152 (1981). https://doi.org/10.1007/BF00540323

[7] Wang W., Zhou G., Yu B., Peng M.: New reactive rigidrod aminated aromatic polyamide for the simultaneous strengthening and toughening of epoxy resin and carbon fiber/epoxy composites. Composites Part B: Engineering, 197, 108044/1-108044/9 (2020).

https://doi.org/10.1016/j.compositesb.2020.108044

[8] Jayan J. S., Deeraj B. D. S., Saritha A., Joseph K.: Theoretical modelling of kinetics of glass transition temperature of PEG toughened epoxy. Plastics, Rubber and Composites, 49, 237-244 (2020).

https://doi.org/10.1080/14658011.2020.1732124

[9] Thomas R., Sinturel C., Pionteck J., Puliyalil H., Thomas S.: In-situ cure and cure kinetic analysis of a liquid rubber modified epoxy resin. Industrial and Engineering Chemistry Research, 51, 12178-12191 (2012). https://doi.org/10.1021/ie2029927

[10] Bach Q-V., Vu C. M., Vu H. T., Vu H. B., Nguyen T. V., Chang S. W., Nguyen D. D., Thi T. A. D., Doan V. N.: Significant enhancement of fracture toughness and mechanical properties of epoxy resin using CTBN-grafted epoxidized linseed oil. Journal of Applied Polymer Science, 137, 48276/1-48276/9 (2019).

https://doi.org/10.1002/app.48276
[11] Dadian A., Rahnama S., Zolfaghari A.: Experimental study of the CTBN effect on mechanical properties and mode I and II fracture toughness of a new epoxy resin. Journal of Adhesion Science and Technology, 34, 2389 2404 (2020). https://doi.org/10.1080/01694243.2020.1763540

[12] Ren X., Tu Z., Wang J., Jiang T., Yang Y., Shi D., Mai Y-W., Shi H., Luan S., Hu G-H.: Critical rubber layer thickness of core-shell particles with a rigid core and a soft shell for toughening of epoxy resins without loss of elastic modulus and strength. Composites Science and Technology, 153, 253-260 (2017).

https://doi.org/10.1016/j.compscitech.2017.10.027

[13] Yahyaei H., Ebrahimi M., Tahami H. V., Mafi E. R., Akbarinezhad E.: Toughening mechanisms of rubber modified thin film epoxy resins: Part 2 - Study of abrasion, thermal and corrosion resistance. Progress in Organic Coatings, 113, 136-142 (2017).

https://doi.org/10.1016/j.porgcoat.2017.09.007

[14] Wu S., Guo Q., Peng S., Hameed N., Kraska M., Stühn B., Mai Y. W.: Toughening epoxy thermosets with block ionomer complexes: A nanostructure-mechanical property correlation. Macromolecules, 45, 3829-3840 (2012). https://doi.org/10.1021/ma300458y

[15] Yu W., Fu J., Dong X., Chen L., Jia H., Shi L.: Highly populated and nearly monodispersed nanosilica particles in an organic medium and their epoxy nanocomposites. ACS Applied Materials and Interfaces, 5, 88978906 (2013). https://doi.org/10.1021/am402845d

[16] Zotti A., Zuppolini S., Borriello A., Zarrelli M.: Effect of $\mathrm{SiO}_{2} @$ polydopamine core/shell nanoparticles as multifunctional filler for an aeronautical epoxy resin. Materials Today: Proceedings, 34, 117-120 (2020). https://doi.org/10.1016/j.matpr.2020.01.407

[17] Zhu M., Liu L., Wang Z.: Iron-phosphorus-nitrogen functionalized reduced graphene oxide for epoxy resin with reduced fire hazards and improved impact toughness. Composites Part B: Engineering, 199, 108283/1108283/12 (2020). https://doi.org/10.1016/j.compositesb.2020.108283

[18] Dittanet P., Pearson R. A.: Effect of bimodal particle size distributions on the toughening mechanisms in silica nanoparticle filled epoxy resin. Polymer, 54, 18321845 (2013). https://doi.org/10.1016/j.polymer.2012.12.059

[19] Bray D. J., Dittanet P., Guild F. J., Kinloch A. J., Masania K., Pearson R. A., Taylor A. C.: The modelling of the toughening of epoxy polymers via silica nanoparticles: The effects of volume fraction and particle size. Polymer, 54, 7022-7032 (2013).

https://doi.org/10.1016/j.polymer.2013.10.034

[20] Martinez-Rubi Y., Ashrafi B., Guan J., Kingston C., Johnston A., Simard B., Mirjalili V., Hubert P., Deng L., Young R. J.: Toughening of epoxy matrices with reduced single-walled carbon nanotubes. ACS Applied Materials and Interfaces, 3, 2309-2317 (2011). https://doi.org/10.1021/am200523z 
[21] Ahmed M. A., Kandil U. F., Shaker N. O., Hashem A. I.: The overall effect of reactive rubber nanoparticles and nano clay on the mechanical properties of epoxy resin. Journal of Radiation Research and Applied Sciences, 8, 549-561 (2015).

https://doi.org/10.1016/j.jrras.2015.06.010

[22] Kothmann M. H., Zeiler R., de Anda R., Brückner A., Altstädt V.: Fatigue crack propagation behaviour of epoxy resins modified with silica-nanoparticles. Polymer, 60, 157-163 (2015).

https://doi.org/10.1016/j.polymer.2015.01.036

[23] Carballeira P., Haupert F.: Toughening effects of titanium dioxide nanoparticles on $\mathrm{TiO}_{2} /$ epoxy resin nanocomposites. Polymer Composites, 31, 1241-1246 (2009). https://doi.org/10.1002/pc.20911

[24] Karthikeyan L., Robert T. M., Mathew D., Suma D. D., Thomas D.: Novel epoxy resin adhesives toughened by functionalized poly (ether ether ketone) s. International Journal of Adhesion and Adhesives, 106, 102816/1102816/11 (2021). https://doi.org/10.1016/j.jiadhadh.2021.102816

[25] Dhevi D. M., Jaisankar S. N., Pathak M.: Effect of new hyperbranched polyester of varying generations on toughening of epoxy resin through interpenetrating polymer networks using urethane linkages. European Polymer Journal, 49, 3561-3572 (2013). https://doi.org/10.1016/j.eurpolymj.2013.06.041

[26] Rong M., Zeng H.: Polycarbonate-epoxy semi-interpenetrating polymer network: 2 . Phase separation and morphology. Polymer, 38, 269-277 (1997). https://doi.org/10.1016/S0032-3861(96)00500-9

[27] Pang B., Jia Y., Pang S. D., Zhang Y., Du H., Geng G., Ni H., Qian J., Qiao H., Liu G.: The interpenetration polymer network in a cement paste-waterborne epoxy system. Cement and Concrete Research, 139, 106236/1106236/14 (2021).

https://doi.org/10.1016/j.cemconres.2020.106236

[28] Ma S., Guo J.: Preparation and properties of organoclay/polyethersulfone/epoxy resin hybrid nanocomposites (in Chinese). Chinese Journal of Materials Research, 28, 794-800 (2014).

https://doi.org/10.11901/1005.3093.2014.221

[29] Rong M., Zeng H.: Polycarbonate/epoxy semi-interpenetrating polymer network: 1 . Preparation, interaction and curing behaviour. Polymer, 37, 2525-2531 (1996). https://doi.org/10.1016/0032-3861(96)85368-7

[30] Ru C., Gu Y., Duan Y., Na H., Zhao C.: Nafion based semi-interpenetrating polymer network membranes from a cross-linkable SPAEK and a fluorinated epoxy resin for DMFCs. Electrochimica Acta, 324, 134873/1134873/8 (2019).

https://doi.org/10.1016/j.electacta.2019.134873
[31] Danso R., Hoedebecke B., Whang K., Sarrami S., Johnston A., Flipse S, Wong N., Rawls H. R.: Development of an oxirane/acrylate interpenetrating polymer network (IPN) resin system. Dental Materials, 34, 1459 1465 (2018). https://doi.org/10.1016/j.dental.2018.06.013

[32] Chen T., Mansfeld C. D., Ju L., Braid D. G.: The influence of mechanical recycling on the properties of thermotropic liquid crystalline polymer and long glass fiber reinforced polypropylene. Composites Part B: Engineering, 200, 108316/1-108316/11 (2020).

https://doi.org/10.1016/j.compositesb.2020.108316

[33] Hasan A. M. A., El-Saeed A. M., Al-Shafey H. I., El-Sockary M. A., El-Ghazawy R. A. I.: A preliminary study on liquid crystalline epoxy curatives from natural abietic acid. Egyptian Journal of Petroleum, 28, 127136 (2019).

https://doi.org/10.1016/j.ejpe.2018.12.003

[34] Pourhashem S., Rashidi A., Vaezi M. R., Bagherzadeh M. R.: Excellent corrosion protection performance of epoxy composite coatings filled with amino-silane functionalized graphene oxide. Surface and Coatings Technology, 317, 1-9 (2017).

https://doi.org/10.1016/j.surfcoat.2017.03.050

[35] Meng Y., Zhang X-H., Du B-Y., Zhou B-X., Zhou X., Qi G-R.: Thermosets with core-shell nanodomain by incorporation of core crosslinked star polymer into epoxy resin. Polymer, 52, 391-399 (2011). https://doi.org/10.1016/j.polymer.2010.11.046

[36] Guo W., Nie S., Kalali E. N., Wang X., Wang W., Cai W., Song L., Hu Y.: Construction of SiO2@UiO-66 core-shell microarchitectures through covalent linkage as flame retardant and smoke suppressant for epoxy resins. Composites Part B: Engineering, 176, 107261/1107261/12 (2019).

https://doi.org/10.1016/j.compositesb.2019.107261

[37] Zhang X., Lu X., Qiao L., Jiang L., Cao T., Zhang Y.: Developing an epoxy resin with high toughness for grouting material via co-polymerization method. e-Polymers, 19, 489-498 (2019).

https://doi.org/10.1515/epoly-2019-0052

[38] Zhang X., Qiao L., Lu X., Jiang L., Cao T.: Preparation and properties of toluene-diisocyanate-trimer-modified epoxy resin. Polymers, 11, 416/1-416/12 (2019). https://doi.org/10.3390/polym11030416 